\title{
Qualitative traits and genetic characterization of native chicken (Gallus gallus domesticus) in selected areas of Eastern and Western Samar, Philippines
}

\author{
Cyrill John P. Godinez ${ }^{1 *}$, Masahide Nishibori ${ }^{2}$ and Dinah M. Espina'
}

\begin{abstract}
Submitted: 10 January 2019 | Accepted: 9 January 2020

The Philippines has a number of chicken genetic groups, mostly of non-descript and indigenous type. In view of the need to expand the information on native chicken diversity, this study was conducted to identify distinct qualitative traits and estimate genetic diversity and relationship among native chicken populations in selected areas of Eastern and Western Samar, Philippines. A total of 100 native chickens were qualitatively analyzed using a non-parametric test, and 43 generated mtDNA sequences were used in the genetic analysis. Results revealed significantly different distributions of plumage color among male native chickens and shank color in female native chickens $(p<0.05)$. The occurrence of plumage pattern, earlobe color and shank color for male native chickens and plumage color, plumage pattern, and earlobe color for female native chickens across Samar Island is not different $(p>0.05)$. The genetic relationship showed $41.2 \%$ native chicken populations clustered to a group shared by Red junglefowl and native chicken, $29.4 \%$ clustered to a group closer to White Leghorn, and White Plymouth Rock chicken breeds, $17.6 \%$ clustered to a group shared by G. g. spadiceus and a commercial line, and $11.7 \%$ clustered to a group closer to Rhode Island Red and a commercial egg layer line. Samar native chickens had red (wild-type, $\left.e^{+}\right)$laced $(I g)$ and brown $\left(e^{b}\right)$ pencilled $(P g)$ plumage in rooster and hen, respectively. The phenotypic and genetic information concluded that there is considerable diversity of native chickens in Samar, Philippines. There is a tremendous opportunity to work with larger sample size in the areas where a number of indigenous chickens have not yet been characterized.
\end{abstract}

Keywords: qualitative traits, genetic diversity, mtDNA, native chicken, Samar Philippines

Department Animal Science, Visayas State University, Baybay City, Leyte, Philippines

${ }^{2}$ Graduate School of Biosphere Science, Hiroshima University, 1-4-4 Kagamiyama, Higashi-Hiroshima

City, Japan

*Corresponding Author. Address: Department Animal Science, Visayas State University, Baybay City, Leyte, Philippines; Email:cyrilljohn.godinez@vsu.edu.ph

DOI: $10.32945 /$ atr 4225.2020 


\section{Qualitative traits and genetic characterization of native chicken}

\section{INTRODUCTION}

Domestic chickens are widely farmed around the world, especially in Southeast Asia, as protein sources in the form of meat and eggs, providing food security for rural households (Shand 1997). Other important roles of chickens range from food to entertainment, ornamental purposes, and religious practices. The Philippines is considered as one of the biodiversity hotspots in the Indo-Australian Archipelago (Myers et al 2000). It was reported that 6 out of 243 recorded local poultry breeds in Asia could be found in the Philippines (DAD-IS 2011). The Philippines, like many countries in the world, has a number of chicken genetic groups, mostly nondescript, indigenous types, and commonly referred to as traditional chickens (FAO 2012).

In recent years, there has been a renewed interest in the identification, documentation, and utilization of Philippine native chickens. Information on the phenotypic and molecular genetic characteristics of these chicken populations is very important for strategic decision-making regarding conservation and/or improvement (Boettcher et al 2010). It is essential to design livestock conservation, development, and breeding programs for the management of animal genetic resources at the local, national, regional, and global levels (FAO 2012). The findings of Bejar et al (2012) and Picardal et al (2015) both intensively characterized the Samar native chickens phenotypically, which gave important information on its diversity. However, genetic characterization, especially identifying ancestral lineages of the native chicken populations in the area is limited.

The nucleotide sequence of the mitochondrial D-loop region is an important and powerful molecular tool used to track genetic information about the ancestral breeds of chicken; showing the phylogenetic relationship, genetic diversity, and differentiation within and between populations (Nishibori et al 2004, FAO 2011, Miao et al 2013). The use of maternally inherited mitochondrial DNA (mtDNA), especially its complete displacement-loop (D-loop) region, has been increasingly used over a decade. Hence, this study was conducted to identify distinct morphological traits and estimate the genetic relationship and diversity of native chickens raised locally in Samar, Philippines.

\section{MATERIALS AND METHODS}

\section{Phenotypic Characterization}

A total of 100 samples were collected in geographically selected upland areas of Calbiga, Western Samar ( $n=25)$, Basey, Western Samar $(n=25)$, Lawaan, Eastern Samar $(n=25)$, and Salcedo, Eastern Samar $(n=25)$ (Table 1).

Discrete phenotypic characters were determined by an actual examination of every adult animals following identification indices set by Nishibori et al (2005) and FAO (2012). The data were analyzed for descriptive statistics using frequency procedures of Statistical Packages for Social Sciences (SPSS) version 22. Data on plumage color and pattern, earlobe color, and shank color were analyzed using the Kruskal-Wallis test to examine differences in the morphological characteristics across sampling areas. Significant differences in the frequency of occurrences among sampling areas were analyzed using the least significant differences (LSD) for ranks. 
Godinez, Nishibori \& Espina

Table 1. List of Samar native chicken populations used in the study

\begin{tabular}{lccc}
\hline Species & Phenotype sample & Blood/DNA sample & Source of sample* \\
\hline Native chicken & 25 & $9(3 \odot, 6 \wp)$ & CWS \\
25 & $18(9 \odot, 9 \wp)$ & BWS \\
25 & $13(4 \odot, 9 \wp)$ & LES \\
25 & $3(\odot)$ & SES
\end{tabular}

*CWS=Calbiga Western Samar, LNS=Lavezarez Northern Samar, LES=Lawaan Eastern Samar, BWS=Basey Western Samar, SES=Salcedo Eastern Samar

\section{Genetic Characterization}

\section{DNA extraction, mtDNA amplification and sequencing}

A total of 43 native chicken blood samples were collected randomly, mostly in the upland areas ensuring chickens were not selected from the same family: 9 from Calbiga, Western Samar, 18 from Basey, Western Samar, 13 from Lawaan, Eastern Samar and 3 from Salcedo, Eastern Samar. All blood samples were used as DNA materials in this study (Table 1).

Genomic DNA was extracted from the stored whole blood of the native chickens using phenol-chloroform method.

The amplification for complete mtDNA control region sequence - fragment 5.0 kilobase pairs (kbp) and mtDNA D-loop region, 1.3kbp fragment was amplified using long and accurate - PCR (LA-PCR) kit (Takara Shuzo, Otsu, Japan) with chicken DNA as a template, following established primer set, Cytb-Forward: 5'-TACA CGAATCAGGCTCAAACAACCCCCTAGGCATC-3', 16S-Reverse: 5'-TGCACCATTAG GTTGTCCTGATCCAACATCGAGGT-3' recommended by Nishibori et al (2003). The reaction began with a preliminary denaturation at $94^{\circ} \mathrm{C}$ for $2 \mathrm{~min}$, followed by 30 cycles of DNA denaturation at $98^{\circ} \mathrm{C}$ for $10 \mathrm{~s}$, annealing of primers at $57^{\circ} \mathrm{C}$ for $30 \mathrm{~s}$, primer extension at $68^{\circ} \mathrm{C}$ for $2 \mathrm{~min}$ and $30 \mathrm{~s}$ and $8 \mathrm{~min}$ final extension of primers at $68^{\circ} \mathrm{C}$ using a GeneAmp PCR System 9700 (Applied Biosystems, Foster, USA). The PCR products were electrophoresed on a $1.0 \%$ agarose gel, and visualized by staining with ethidium bromide via ultraviolet transilluminator (UVP Transilluminator - BioDoc-It Imaging System). The PCR products from the segmental amplification were cleaned and purified using Exonuclease 1 (Exo1) and Shrimp Alkaline Phosphatase (SAP) which degrades the residual PCR primers and dephosphorylates the remaining dNTPs, respectively. After purification, the samples were sent to FASMAC Corporation, (5-1-3 Midorigaoka, Atsugi-shi, Kanagawa, Japan) for direct DNA sequencing and fragment analysis.

\section{Data Analysis}

The complete mtDNA D-loop sequences obtained from sequencing companies were initially edited using GENESTUDIOProfessional (sequence analysis software) and aligned using ClustalW (Thomson et al 1994). Aligned nucleotide sequences were edited and viewed using the BioEdit sequence alignment editor (Hall 1999). 


\section{Qualitative traits and genetic characterization of native chicken}

Phylogeny reconstruction using Neighbor-Joining method (Saitou \& Nei 1987) by Molecular Evolutionary Genetics Analysis (MEGA) version 6.0 (Tamura et al 2013) were used to estimate genetic relationships within and among native chickens on Samar Island, Philippines together with reference sequences representing different haplogroups. Nomenclatures of the 13 clades (clades A to I \& clades W to Z) reported by Miao et al (2013) were used as reference for the clade notation. The list of haplotypes used and the corresponding GenBank accession numbers are provided in the supplementary data. Bootstrap values were estimated with 1,000 repetitions.

\section{RESULTS AND DISCUSSION}

\section{Phenotypic Characteristics of Samar Native Chicken}

\section{Plumage color}

In this study, 41 male and 59 female native chickens were characterized phenotypically (Table 2 ). The results showed that among male native chickens, six allelomorphic plumage colors were observed across sampling areas (Figure 1). The most observed plumage colors among male native chickens were red (wild-type, $e^{+}$) and silver sex-linked (S). Unique plumage color of domestic chickens also spotted in the island. The birchen $\left(E^{R}\right)$ plumage color $(4.9 \%)$ having dark wild-type with finely stippled wing bays and black sex-linked $\left(B / W / b^{+} / b^{+}\right)$plumage color $(9.8 \%)$ which is believed to be due to the sex-linked crosses between Barred Plymouth Rock females and Rhode Island Red or New Hampshire males (Crawford 1990).

In hens, 9 different allelomorphic plumage colors across sampling areas were observed. Brown ( $\left.e^{b}\right)$ plumage color was observed the highest $(23.7 \%)$, followed by recessive wheaten $\left(e^{y}\right)(16.9 \%)$. (Table 2; Figure 2$)$. However, statistical analysis revealed that the distribution of each plumage color assigned with a relative gene constitution was only different among male native chickens $(p<0.05)$ and not in female native chickens $(p>0.05)$. Male native chickens from Calbiga, Western Samar, were observed to be different between sampling areas.

The higher occurrence of red plumage color (wild-type, $e^{+}$) in roosters and brown plumage color $\left(e^{b}\right)$ in hens agreed with the findings of Cabarles et al (2012) in Western Visayas and Picardal et al (2015) in Eastern Samar that these chickens may be descended from their progenitor possibly through natural selection or to a lesser extent through artificial selection done by the local people.

According to Paxton (2009), the dominant red with combined gold and darkmaroon coloration in roosters and brown colorations in hens could be due to varying levels of two classes of melanin pigments, eumelanin and phaeomelanin. However, eumelanin gives rise to black and dark brown hues, and phaeomelanin produces a reddish-brown color (McGraw 2006). The wild-type $\left(e^{+}\right)$plumage color is reported to be completely dominant to brown and recessive wheaten. The degree of dominance appears to be influenced by modifying genes capable of enhancing and inhibiting the expression of eumelanin. The existence of two wheaten alleles with almost similar phenotypic effects, but marked differences in their dominance relationships, is unusual and interesting. However, consistent results revealed by Crawford (1990), indicated that either two separate alleles or a single wheaten gene are very closely linked to a modifier of eumelanic expression. 


\section{Godinez, Nishibori \& Espina}

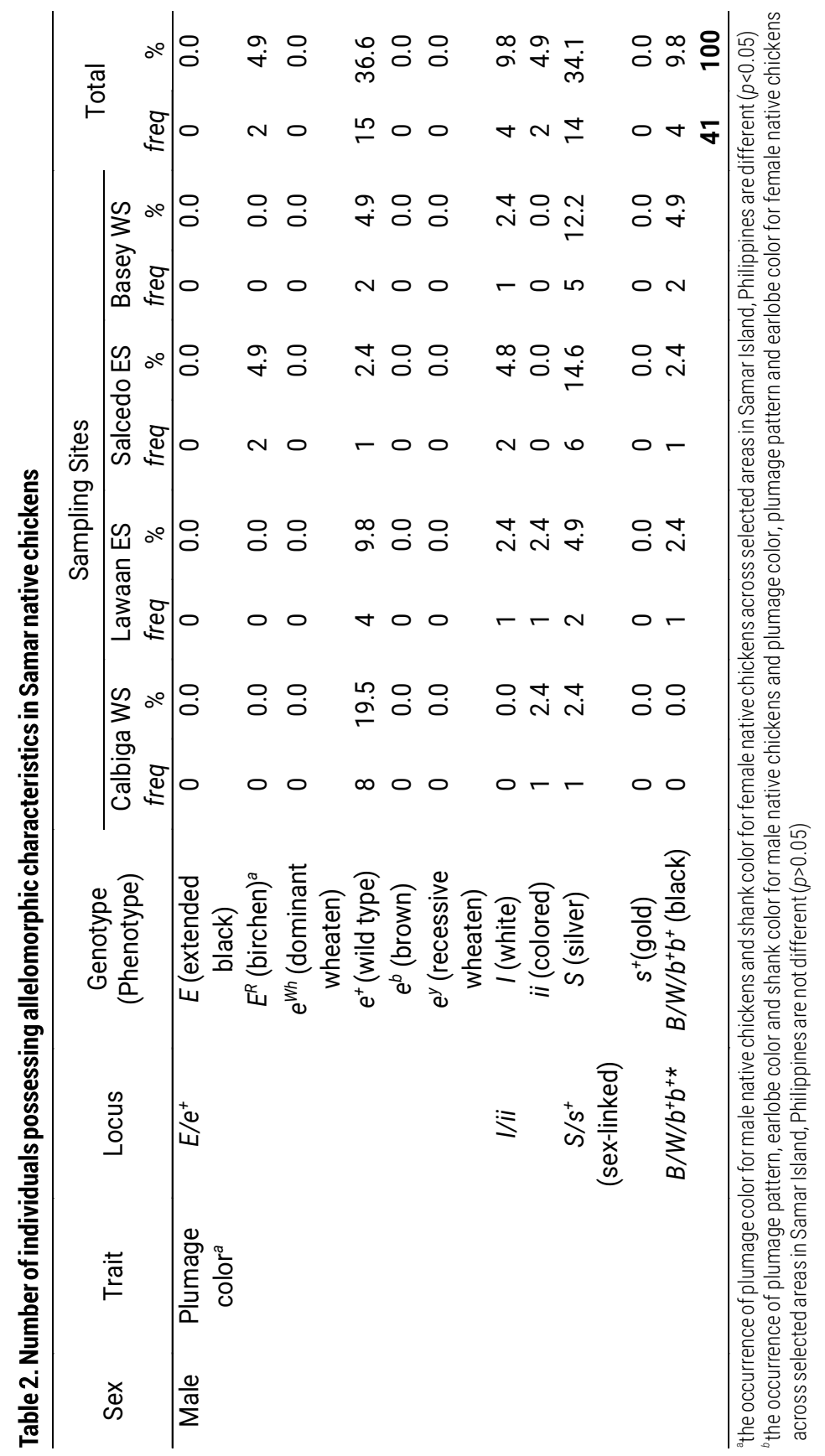


Qualitative traits and genetic characterization of native chicken

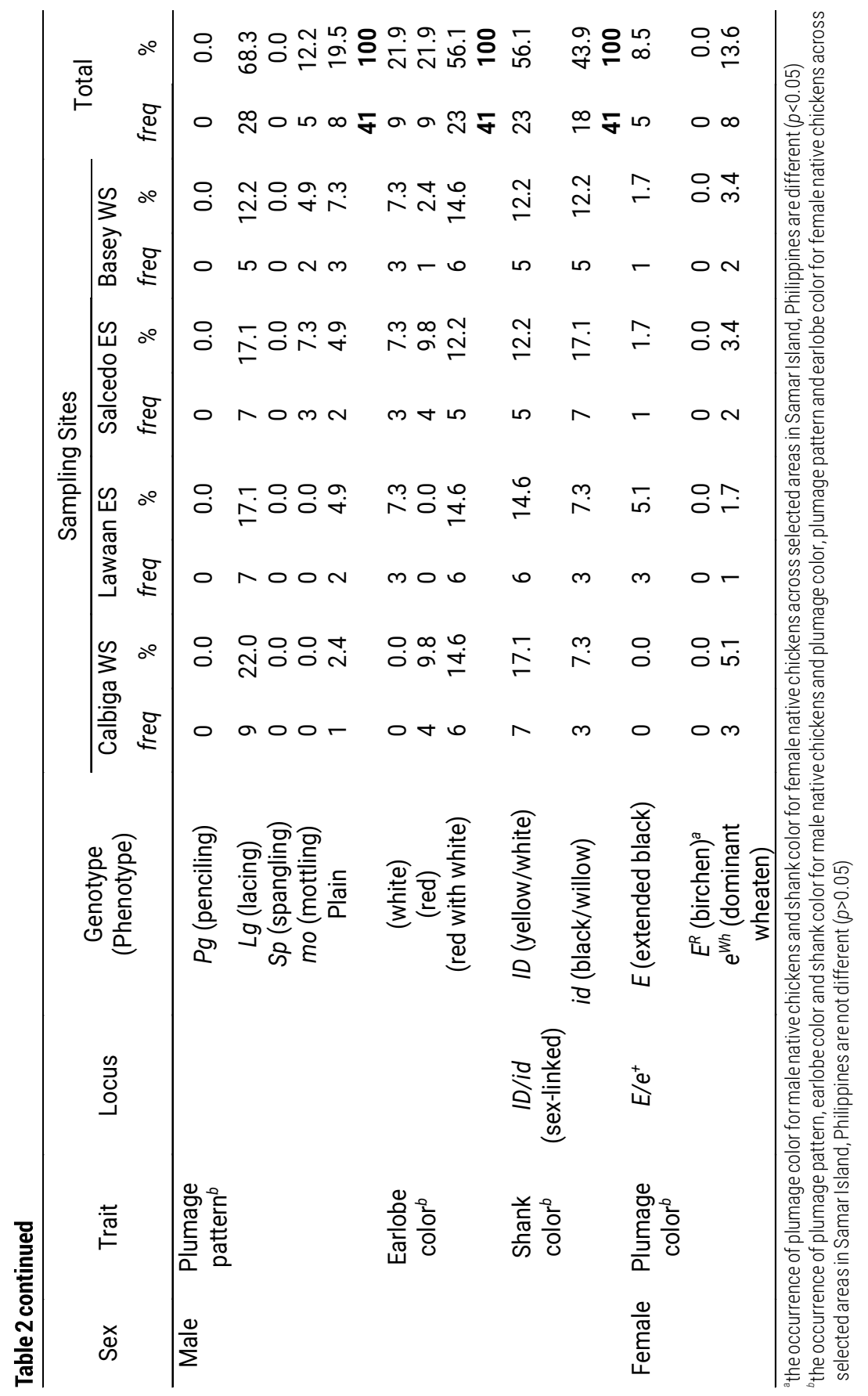


Godinez, Nishibori \& Espina

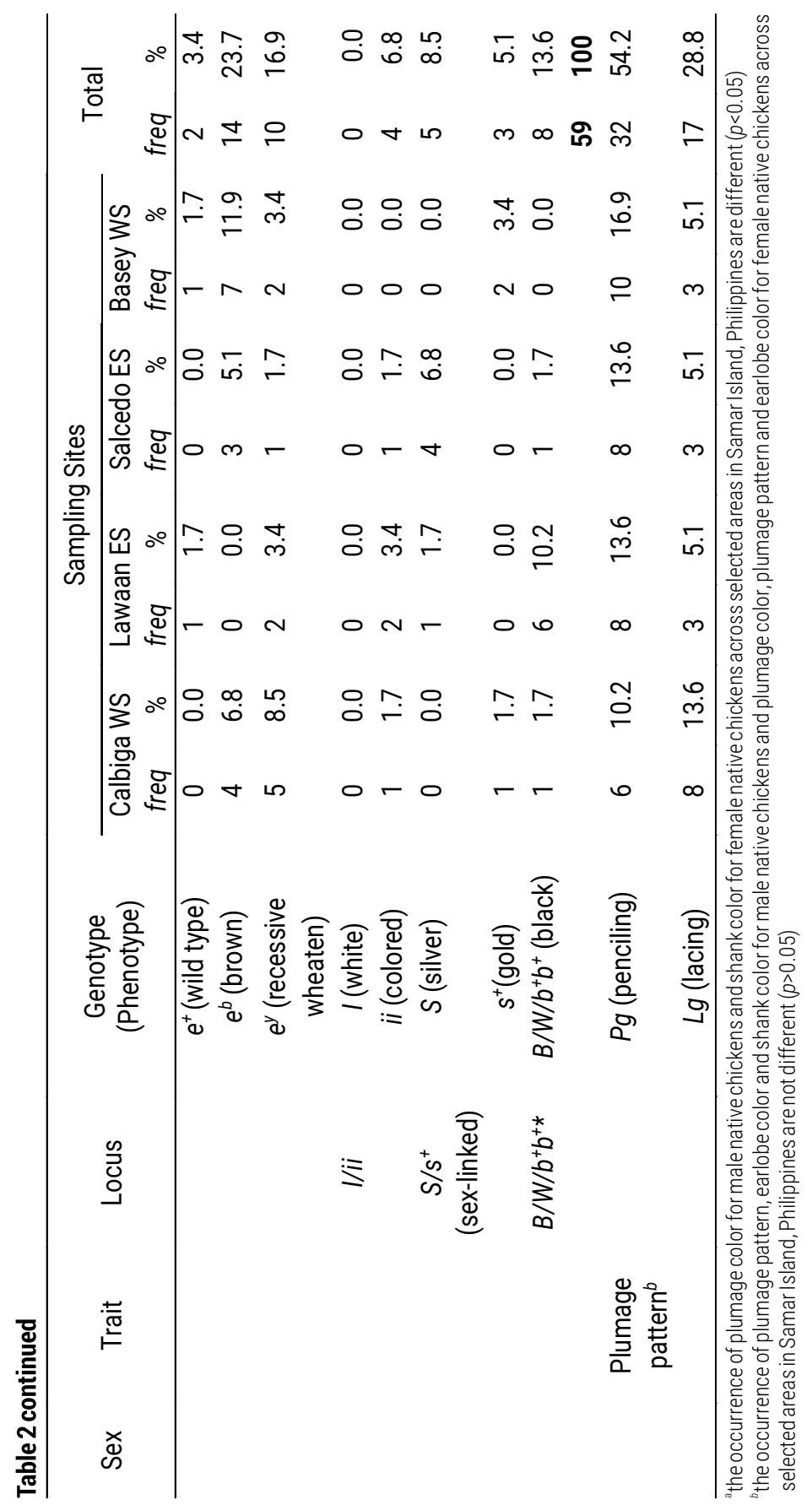


Qualitative traits and genetic characterization of native chicken

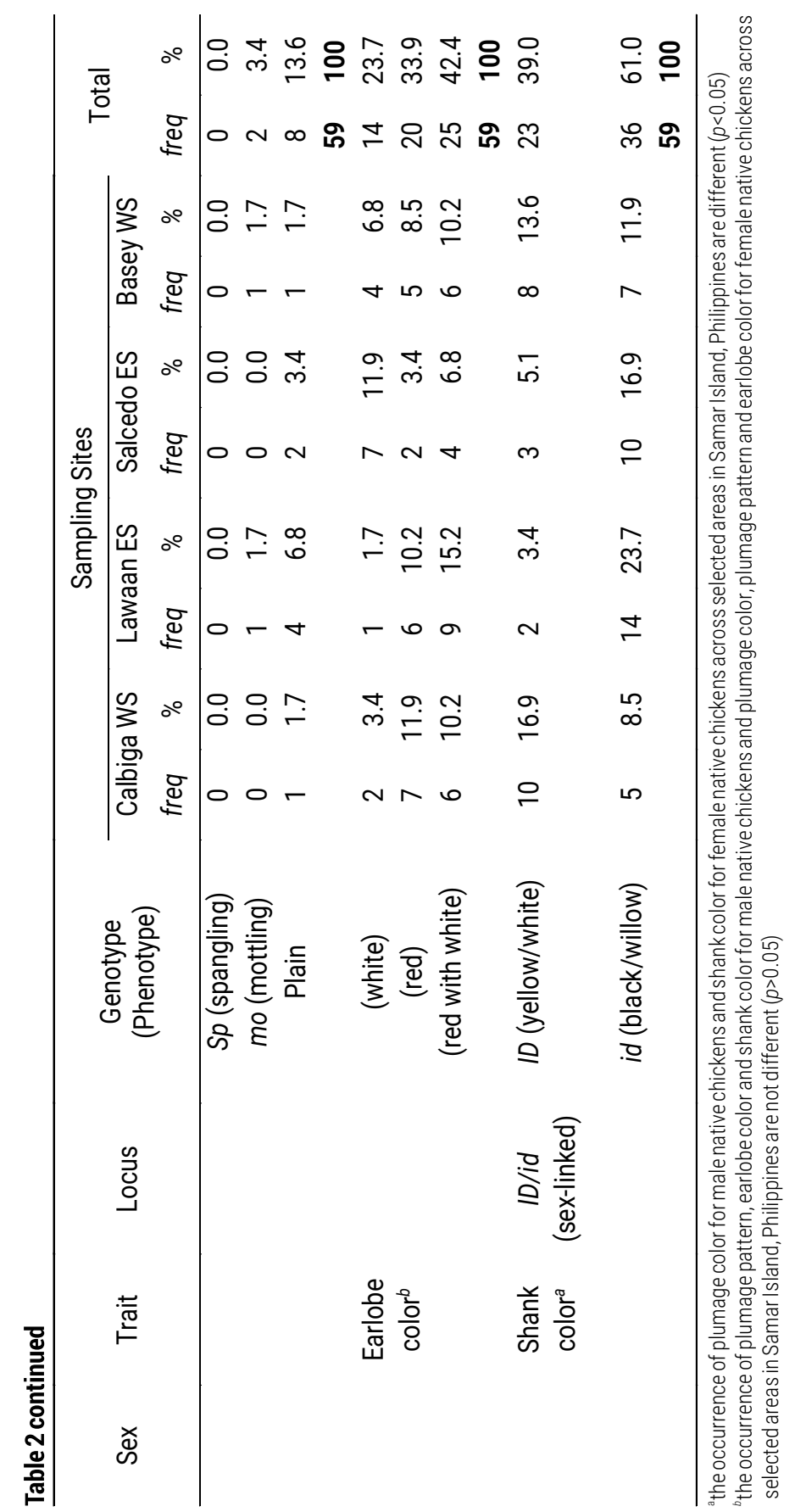


Godinez, Nishibori \& Espina

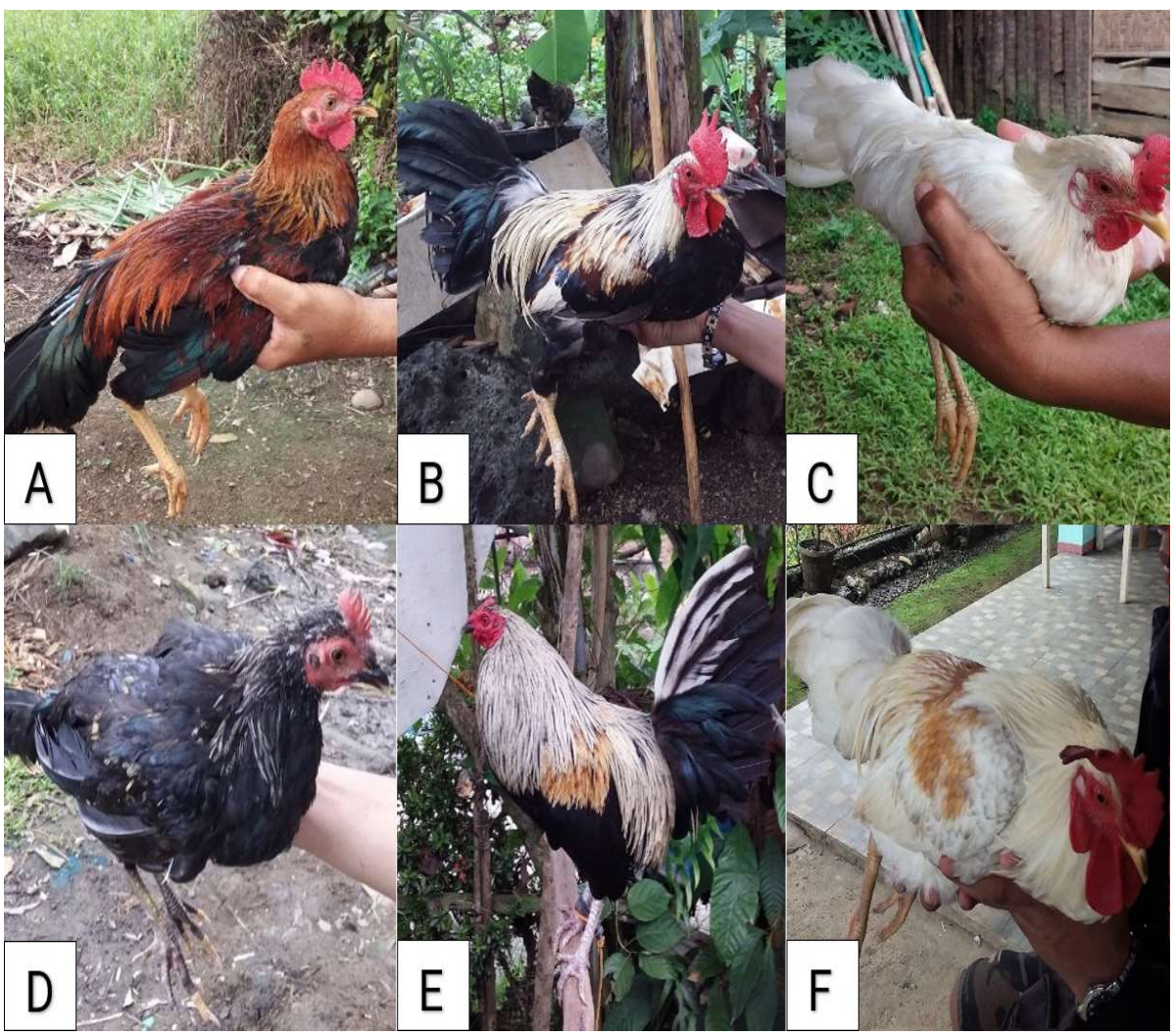

Figure 1. Six different allelomorphic plumage color in male native chickens in Samar Island, Philippines. (A) wild-type ( $\mathrm{e}^{+}$), (B) silver sex-linked (S), (C) plain-white (I), (D) black sex-linked $\left(B / W / b^{+} / b^{+}\right)$, (E) birchen $\left(E^{R}\right)$, and $(F)$ colored (ii)

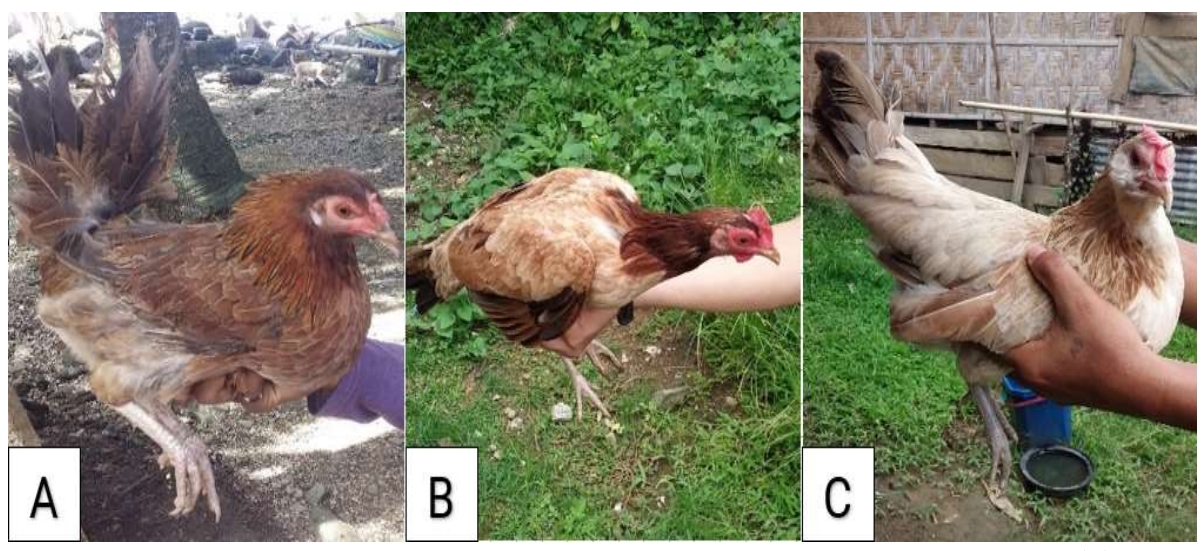

Figure 2. Nine different allelomorphic plumage color in female Samar native chickens. (A) brown $\left(e^{b}\right),(B)$ recessive wheaten $\left(e^{y}\right),(C)$ dominant wheaten $\left(e^{w h}\right),(D)$ black sex-linked $\left(B / W / b^{+} / b^{+}\right),(E)$ extended black (E), (F) silver sex-linked (S), (G) colored (ii), (H) gold sex-linked (s'), and (I) wildtype $\left(\mathrm{e}^{+}\right)$ 


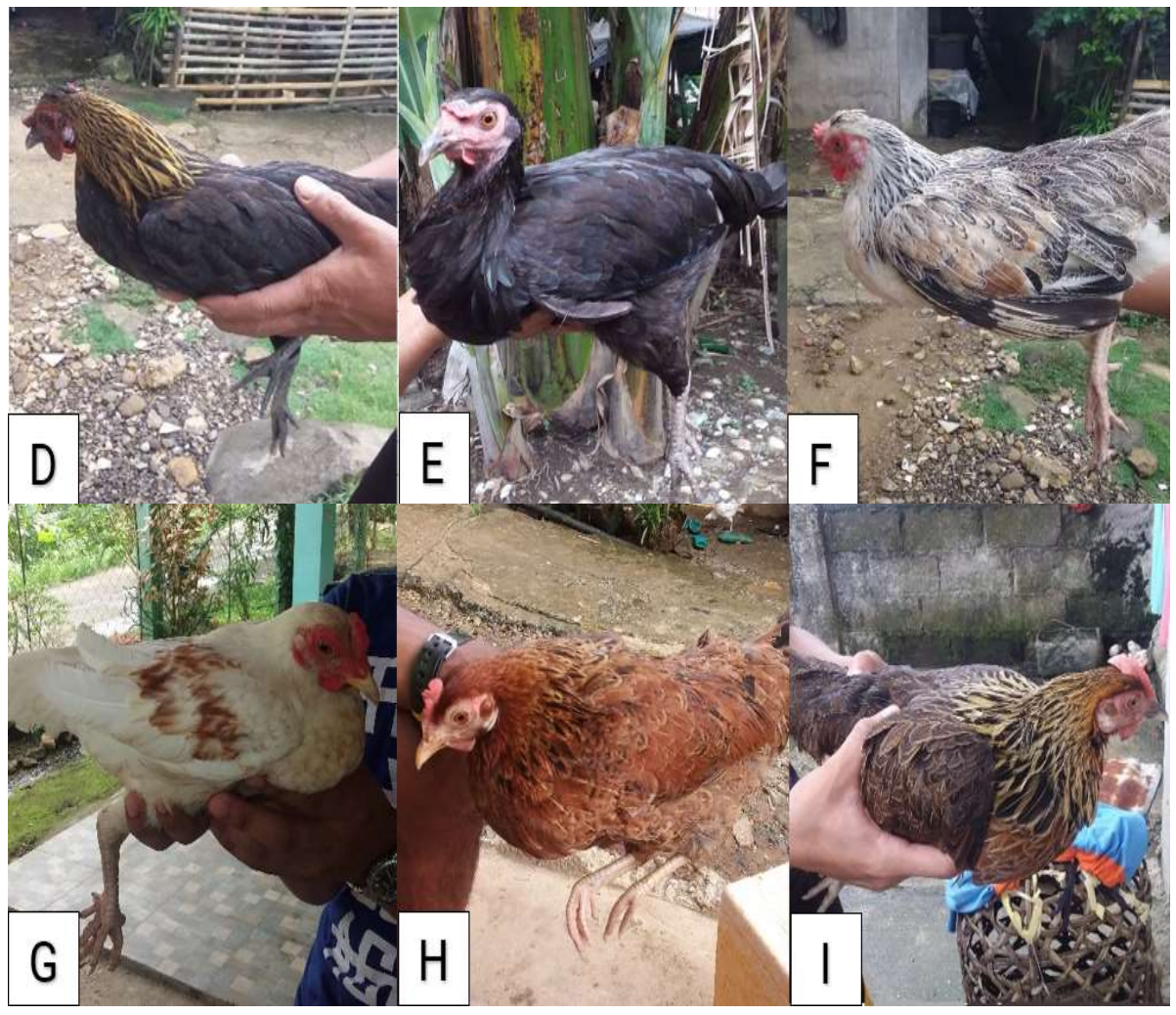

Figure 2 continued

\section{Plumage Pattern}

Statistical analysis revealed that the distribution of each plumage pattern regardless of sex was not different $(p>0.05)$ across sampling areas in Samar Island (Table 2). Result displayed that $68.3 \%$ of the 59 roosters had laced-plumage pattern and 19.5 percent plain-plumage pattern (Table 2; Figure 3 ). In hens, $54.2 \%$ had pencilled-plumage pattern, followed by laced-plumage pattern (28.8\%), plainplumage pattern (13.6\%) and mottled-plumage pattern (3.4\%) had the least. (Table 2; Figure 4).

Results coincided with the findings of Cabarles et al (2012) in Western Visayas native chickens where the laced-plumage pattern for roosters and pencilledplumage pattern for hens were the most observed plumage patterning. Although this is opposed to the findings of Salces et al (2015) with predominant plainplumage pattern in Boholano native chickens. The plumage of chickens is displayed by the arrangement of feathers with various pigmentation patterns. According to Smyth (1990), the color patterns are due to the distribution of eumelanin and the presence or absence of pheomelanin at the feather developmental stage. The position of feather on the body may also affect the expression of color pattern because of differences in the intensity of melanin pigmentation in the skin (Yu et al 2004). 
Godinez, Nishibori \& Espina

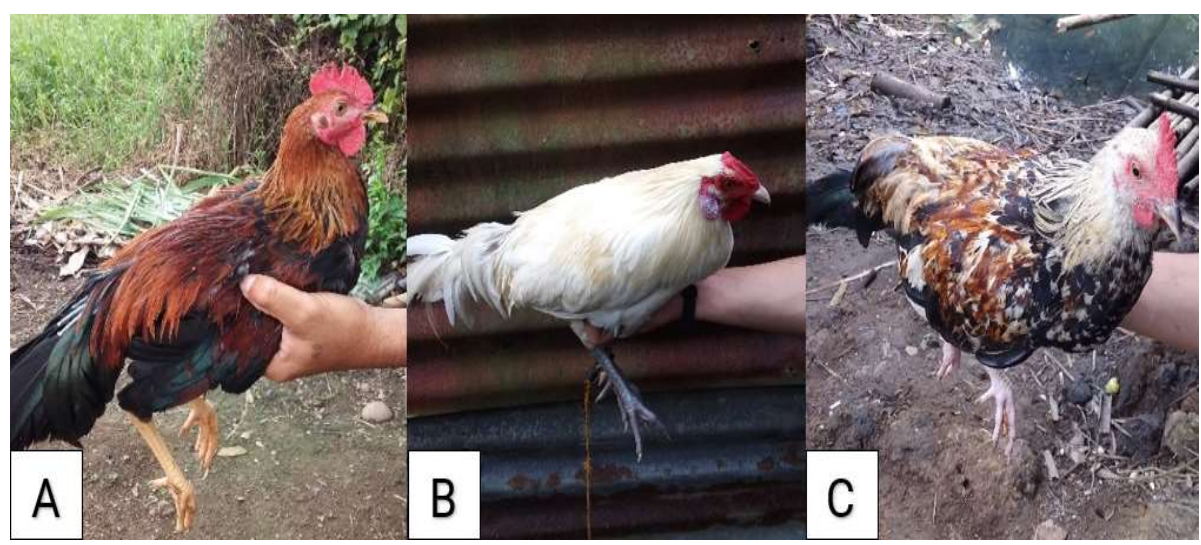

Figure 3. Three different allelomorphic plumage pattern in male Samar native chickens. (A) lacing (lg), (B) plain, and (C) mottling (mo)

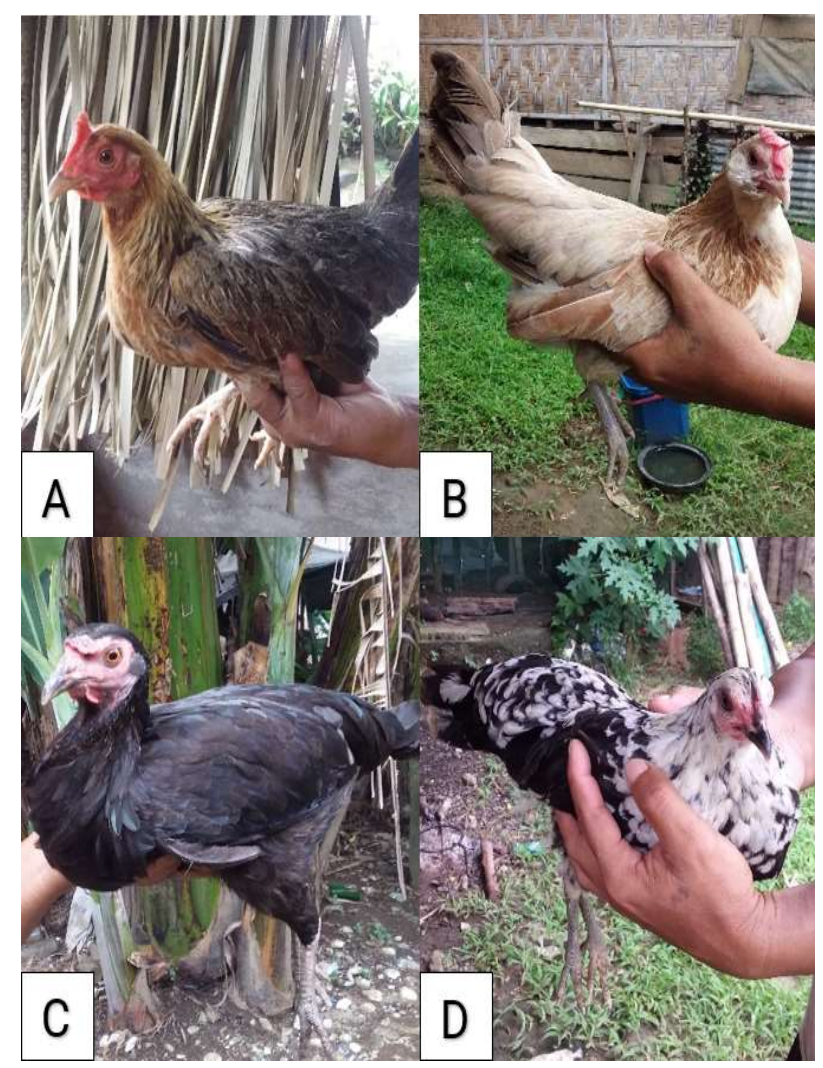

Figure 4. Four different allelomorphic plumage pattern in female Samar native chickens; (A) pencilling ( $\mathrm{Pg})$, (B) lacing (Ig), (C) plain, and mottling (mo) 


\section{Qualitative traits and genetic characterization of native chicken}

\section{Earlobe Color}

It was observed that $56.1 \%$ of the 41 characterized male native chickens had red with white earlobes, followed by the same occurrences of the white earlobes and red earlobes at $21.9 \%$ each (Table 2; Figure 5). Among hens, $42.4 \%$ of the 59 characterized female native chickens had red with white earlobe color. This was followed by $33.9 \%$ red earlobe, while white earlobe occurred the least with $23.7 \%$ (Table 2; Figure 6). However, statistical analysis revealed that the distribution of each earlobe color regardless of sex was not different $(p>0.05)$ across sampling areas in Samar Island.

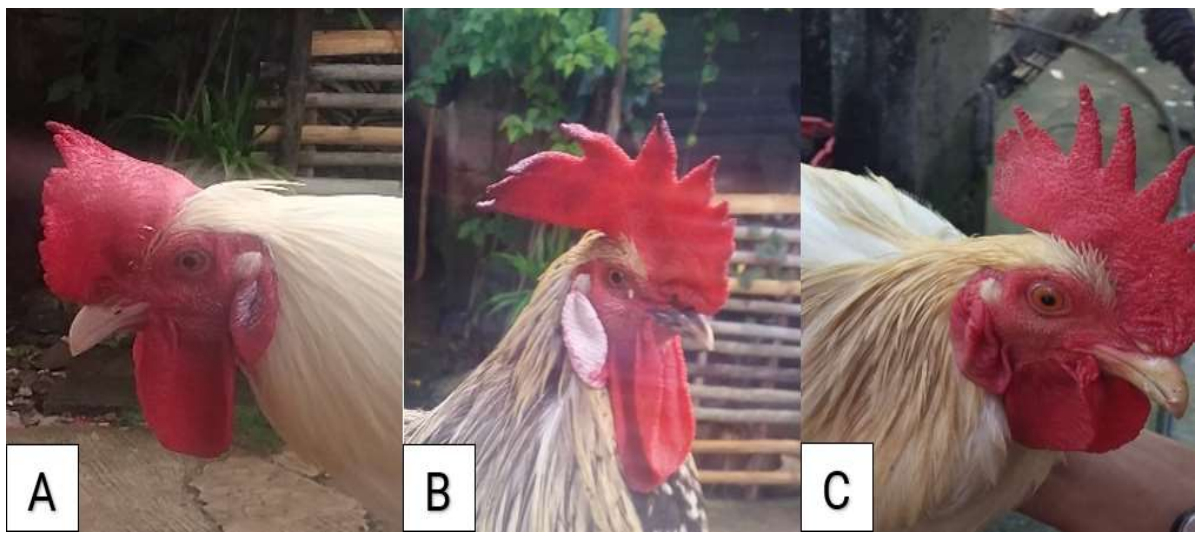

Figure 5. Earlobe color among male native chickens in Samar Island, Philippines: (A) red with white earlobe, (B) white earlobe and (C) red earlobe

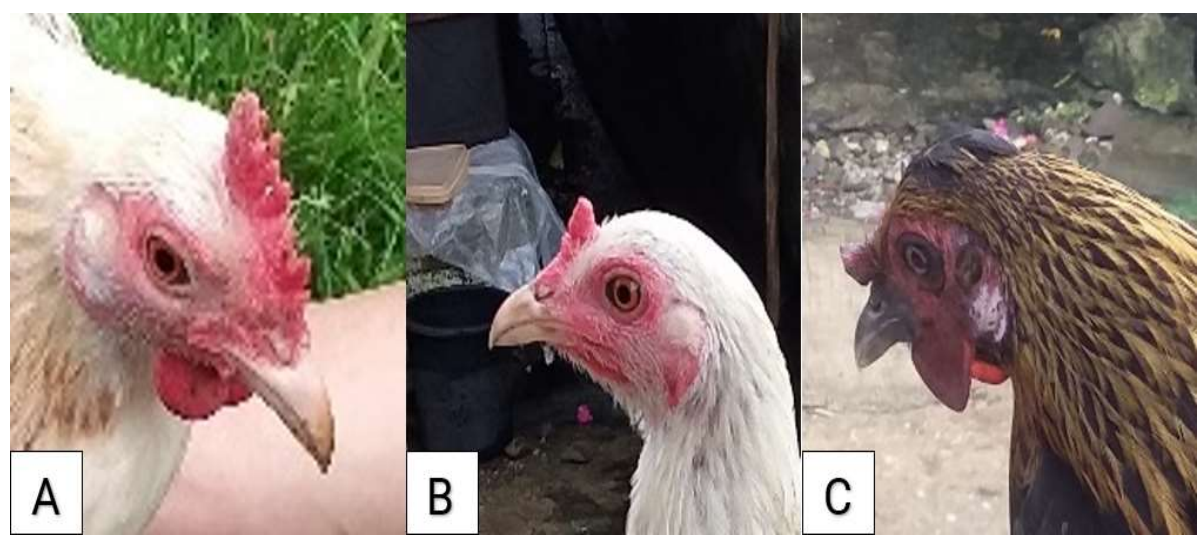

Figure 6. Earlobe color among female native chickens in Samar Island, Philippines: (A) red with white earlobe, (B) red earlobe and (C) white earlobe

The diversity of earlobe colors can be due to the variability of ancestral lineages and mutations which possibly occurred 1,000 years ago resulting from hybridization between subspecies of Gallus gallus, particularly G. g. gallus which carries white earlobes crossed with G. g. spadiceus and G. g. jabouillei, which possessed red color earlobes (Nishida et al 2000). The results of phylogenetic 
analysis (Figure 8 ) revealed $17.6 \%$ of the characterized native chickens clustered closer to G. g. spadiceus species, which is extensively known to have red color earlobe, and $11.7 \%$ closer to a clade of Rhode Island Red and a commercial layer line. These findings demonstrated that the distinctly observed higher occurrences of red with white color earlobes among Samar native chickens were due to considerable crossbreeding interferences between indigenous native chickens and commercial breed lines.

\section{Shank Color}

It was found that $54 \%$ of the 100 characterized native chickens had black or willow shank color (id gene constitution), while $46 \%$ had white or yellow shank (ID gene constitution) (Table 2; Figure 7). Among roosters, $43.9 \%$ possessed black or willow shank, while $56.1 \%$ had white or yellow. In hens, $61 \%$ had black color shank (id), while $39 \%$ had white or yellow shank (ID). However, statistical analysis revealed that the distribution of each shank color with a relative gene constitution was only different among female native chickens $(p<0.05)$ and not in male native chickens $(p>0.05)$. Female native chickens from Lawaan, Eastern Samar, were observed to be different between sampling areas.

The diversity in shank color can be due to interactions of major and modifier genes as pointed out by Smyth (1990). This is controlled by dermal melanin (idt), inhibition of dermal melanin (Id), black extension factor $(E)$ and autosomal white $(W+)$ genes located in the $Z$ chromosome. Id and $i d+$ expression are confined in the dermis, whereas $E$ and $W+$ are in the epidermis. Homozygosity to $E$ in chickens will express black shank. The interactions of $i d+$ and $E$ with dominant white $(I)$ chickens will express slate or willow shank. The presence of sex-linked barring, mottling and wheaten genes will inhibit the expression of $i d+$. Barring makes the pigmentation of the shank lighter in roosters than in hens, whereas mottling expressed small black spots in the white shank. The presence of $W+$ interacting with melanin will appear as blue or slate shank and the $w$ for green or willow. Yellow shank is due to the interaction of homozygous recessive for $w$ and $e+$ with homozygous $I d$, whereas white shank is brought about by the accumulated effects of $W+/ W+I d / I d e+/ e+$.

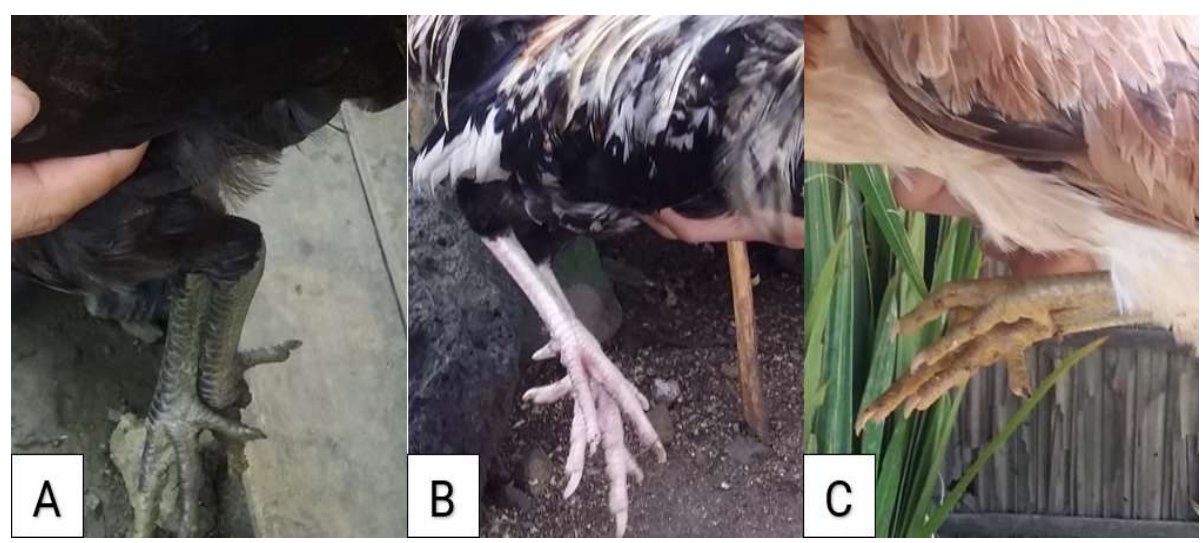

Figure 7. Shank color among native chickens in Samar Island, Philippines; (A) black/willow shank color, (B) white shank color and (C) yellow shank color 
Qualitative traits and genetic characterization of native chicken

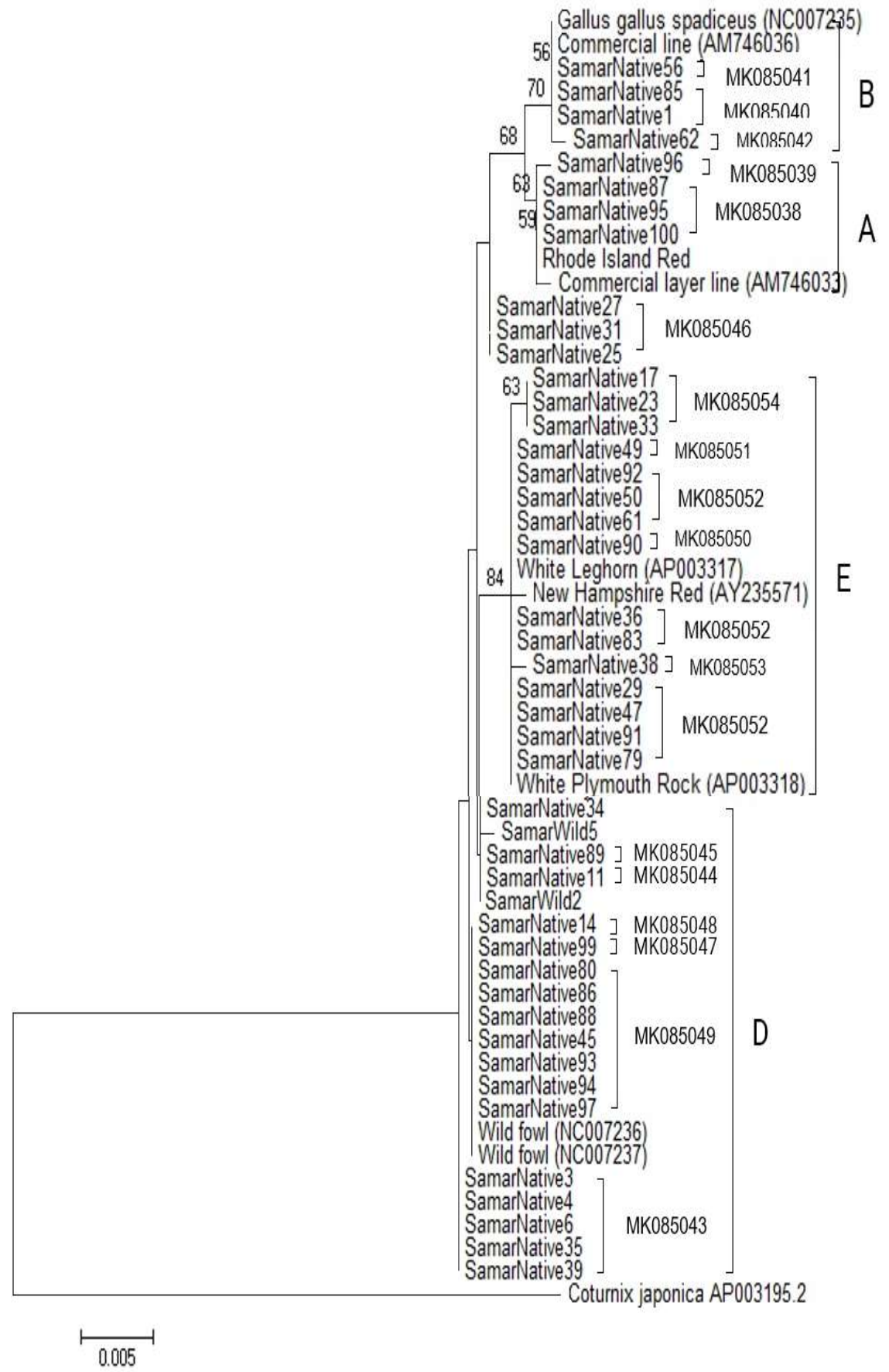

Figure 8. Phylogenetic tree of 55 complete mtDNA D-loop nucleotide sequences ( 45 from this study and 10 derived from Genbank) based on the neighbor joining method (Saitou \& Nei 1987). The numeral at each branch indicates the bootstrap value of replications. Bootstrap values lower than $\mathbf{5 0} \%$ are not shown. The scale bar represents substitution rate per site. Coturnix japonica represent as outgroup. Letter notation A, B, D, and E represents haplogroups 
Godinez, Nishibori \& Espina

\section{Genetic Characteristics of Samar Native Chicken}

\section{Phylogenetic structure and sequence variation of Samar native chickens}

Phylogenetic analysis of Samar native chickens was constructed along with the reference sequences derived from Genbank (Figure 8). The mutational motif in the D-loop sequences of Samar native chickens showed $41.2 \%$ clustered to a haplogroup shared by red junglefowl and native chicken, $29.4 \%$ clustered to a haplogroup closer to White Leghorn and White Plymouth Rock breeds, $17.6 \%$ clustered to a haplogroup shared by G. g. spadiceus and a commercial line, and $11.7 \%$ clustered to a haplogroup closer to Rhode Island Red and a commercial egg layer line.

Phylogeographic studies have identified that one mtDNA lineage (haplogroup D) was largely limited to the Asia-Pacific region and that haplogroup $A, B$, and $E$ contain mtDNA control region haplotypes from all over Eurasia (Liu et al 2006). Haplogroup $E$ is predominant among Indian, Middle Eastern, and European chickens, with the primary subhaplogroup $E 1$ which is the single most-common chicken haplotype found around the world, while haplogroup A and B predominate among South and Eastern Chinese and Japanese chickens (Gongora et al 2008). The updated perspective of chicken domestication had classified the wild fowls in the Philippines as belonging to DI subhaplogroup (Miao et al 2013). Haplogroups A, $B, D$, and $E$ provide insights into the mtDNA signatures of ancient Asia-Pacific chickens and showed agreement with several genealogical findings done across Asia-Pacific region.

The result of this study strongly agreed with the haplogroup classification examined by Miao et al (2013) since Samar native chicken haplotypes revealed higher percentage clustered to subhaplogroup $D 1$, where haplotypes observed to have 5 unique polymorphic sites at the nucleotide base 281, 296, 306, 342 and 686 (Table 3). The D-loop sequence information of $46.5 \%$ (20/43) of the Samar native chickens revealed subhaplogroup $D 1$ as the most widely distributed matrilineal lineage, which is believed to be the haplogroup signature of shared red junglefowls and domestic chickens. Moreover, 34.9\% (15/43) of Samar native chickens classified into subhaplogroup E1 showed 3 unique polymorphic sites at the nucleotide base 217,446 and 1,214 (Table 3). This was believed to be the haplogroup signature of shared domestic chickens and commercial breed lines. An additional 9.3\% (4/43) of Samar native chickens classified as haplogroup A which showed two unique polymorphic sites at the nucleotide base 167 and 225, and lastly, another $9.3 \%$ (4/43) classified as haplogroup B which showed one unique polymorphic site at the nucleotide base 792. This is believed to be the haplogroup signature of shared domestic chickens and commercial breed lines (Figure 8). These results were further supported by the findings of Thomson et al (2014), where Philippine chicken populations confined at 4 distinct haplogroup A, B, D, and E with higher spread throughout the haplogroup $D$. 
Qualitative traits and genetic characterization of native chicken

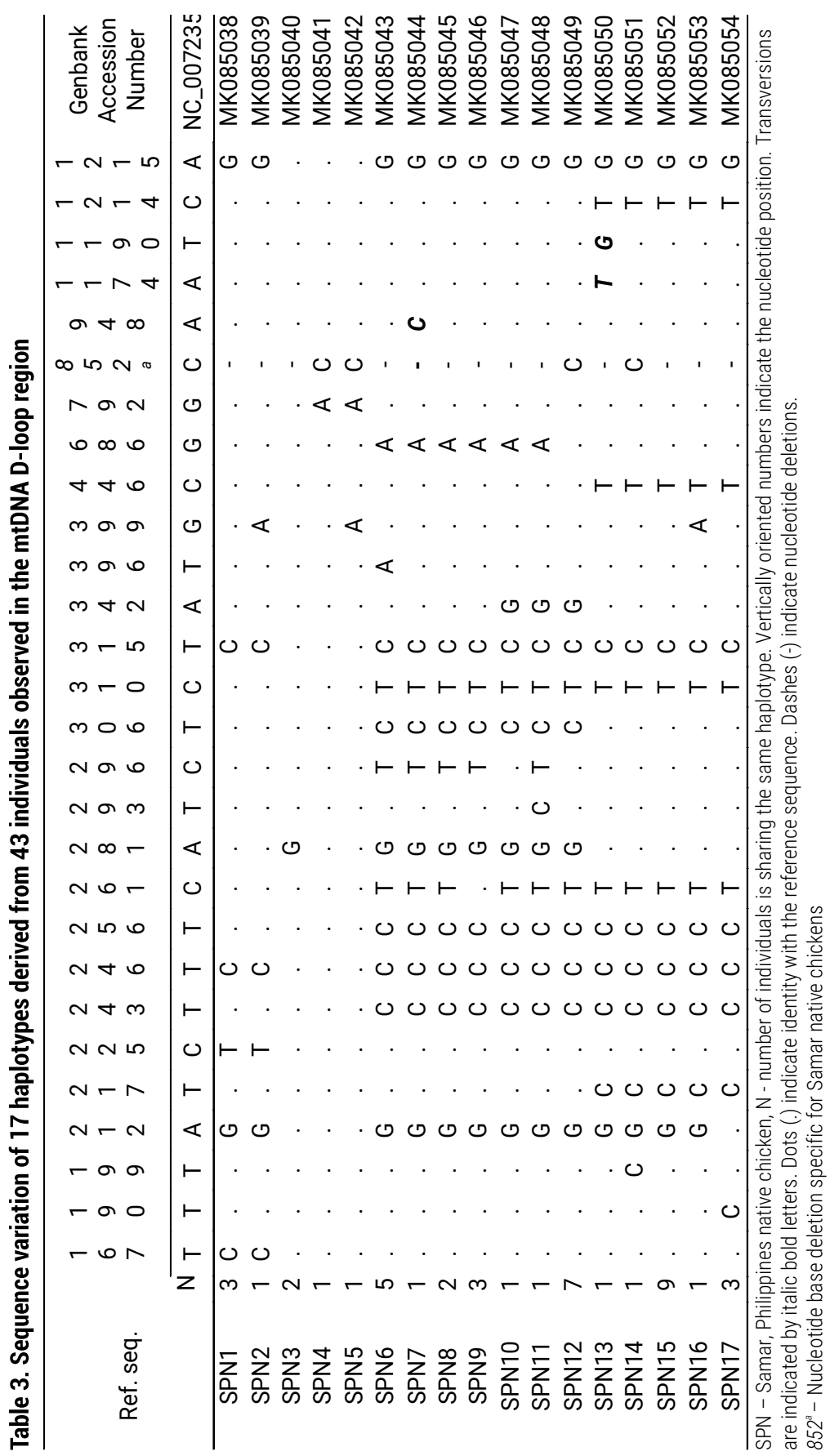


Godinez, Nishibori \& Espina

Results postulated that there are higher populations of native chickens inhabiting Samar, Philippines, which are descendants of shared Samar wild junglefowl and indigenous chickens with a considerable mixture of commercial breed lines. Further, results suggested that Samar native chickens still mingled with red junglefowl species, although others were already a product of crossbreeding of commercial breed lines or a combination of different breeds. This lineage likely changes because human dispersal and migration includes domestic animals and most likely, because of hybridization with commercial hybrid lines both natural and artificial, which is performed by the local people.

For future work, it is suggested to increase the sample size and modify the sampling design such that more areas and upstream villages can be included. Also, considering that Philippines is an archipelago comprising about 7,641 island and a number of islets, there is tremendous opportunity to work in areas where a number of different traditional chickens have not yet been characterized.

\section{ACKNOWLEDGMENTS}

The author wishes to express his gratitude to the farmers in Samar, Philippines. This work was supported in part of Department of Science and Technology, Accelerated Science and Technology Human Resource Development Program (DOST-ASTHRDP) grant.

\section{REFERENCES}

Bejar FR, Baylon MJ, Fabillar JB, Mante LEB, Ultra AA, Aquino RR \& Bejar ET. 2012. Management practices and morphological characterization of indigenous (native) chickens in Samar Province. Discussion Paper Series-Southeast Asian Regional Center for Graduate Study and Research in Agriculture (SEARCA), (2012-3)

Boettcher PJ, Tixier-Boichard M, Toro MA, Simianer H, Eding H, Gandini G, Joost S, Garcia D, Colli L, Ajmone-Marsan P \& Gobaldiv Consortium. 2010. Objectives, criteria and methods for using molecular genetic data in priority setting for conservation of animal genetic resources. Animal Genetics 41(Supplement 1): 64-77

Cabarles JC, Lambio AL, Vega SA, Capitan SS \& Mendioro MS. 2012. Distinct morphological features of traditional chickens (Gallus gallus domesticus L.) in Western Visayas, Philippines. Animal Genetic Resources 51:73-87

Crawford RD. 1990. Poultry Biology: Origin and History of Poultry Species. In Crawford RD (ed) Poultry Breeding and Genetics. Elsevier Science Publishing Company, Amsterdam and New York

Domestic Animal Diversity Information System (DAD-IS). 2011. Breeds Reported by Philippines. Domestic Animal Diversity Information System. http://dad.fao.org

Food and Agriculture Organization of the United Nations (FAO). 2011. Molecular genetic characterization of animal genetic resources. FAO Animal Production and Health Guidelines. No. 9. Rome. http://www.fao.org/3/i2413e/ i2413e00.pdf

Food and Agriculture Organization of the United Nations (FAO). 2012. Phenotypic characterization of animal genetic resources. FAO Animal Production and 


\section{Qualitative traits and genetic characterization of native chicken}

Health Guidelines No. 11. Rome. http://www.fao.org/docrep/015/i2686e/i26 $86 \mathrm{e} 00$

Gongora J, Rawlence NJ, Mobegi VA, Jianlin H, Alcalde JA, Matus JT, Hanotte O, Moran C, Austin JJ, Ulm S \& Anderson AJ. 2008. IndoEuropean and Asian origins for Chilean and Pacific chickens revealed by mtDNA. Proceedings of the National Academy of Sciences 105(30):10308-10313

Hall TA. 1999. BioEdit: a user-friendly biological sequence alignment editor and analysis program for Windows 95/98/NT. Nucleic Acids Symposium Series 41:95-98

Liu YP, Wu GS, Yao YG, Miao YW, Luikart G, Baig M, Beja-Pereira A, Ding ZL, Palanichamy MG \& Zhang YP. 2006. Multiple maternal origins of chickens: out of the Asian jungles. Molecular Phylogenetics and Evolution 38(1):12-19

Mcgraw KJ and Klasing KC. 2006. Carotenoids, immunity, and integumentary coloration in red junglefowl (Gallus gallus). The Auk 123(4):1161-1171

Miao YW, Peng MS, Wu GS, Ouyang YN, Yang ZY, Yu N, Liang JP, Pianchou G, BejaPereira A, Mitra B \& Palanichamy MG. 2013. Chicken domestication: an updated perspective based on mitochondrial genomes. Heredity 110:277-282

Myers N, Mittermeier RA, Mittermeier CG, Da Fonseca GA \& Kent J. 2000. Biodiversity hotspots for conservation priorities. Nature 403:853-858

Nishibori M, Hanazono M, Yamamoto Y, Tsudzuki M \& Yasue H. 2003. Complete nucleotide sequence of mitochondrial DNA in White Leghorn and White Plymouth Rock chickens. Animal Science Journal 74(5):437-439

Nishibori M, Shimogiri T, Hayashi T \& Yasue H. 2005. Molecular evidence for hybridization of species in the genus Gallus except for Gallus varius. Animal genetics 36(5):367-375

Nishibori $M$, Win N, Mannen $H$, Yamagata $T$, Tanaka $K$, Suzuki $Y$, Kurosawa $Y$, Nozawa K, Hla T, Daing T, Nyunt MM, Yamamoto Y \& Maeda Y. 2004. Complete sequence of mitochondrial D-loop region of red junglefowls (Gallus gallus) and their genetic diversity in Myanmar and its neighbor countries. Report of the Society for Researches on Native Livestock 21:213-223

Nishida T, Rerkamnuaychoke W, Tung DG, Saignaleus S, Okamoto S, Kawamoto Y, Kimura J, Kawabe K, Tsunekawa N, Otaka H \& Hayashi Y. 2000. Morphological identification and ecology of the red jungle fowl in Thailand, Laos and Vietnam. Nihon Chikusan Gakkaiho 71(5):470-480

Paxton EH. 2009. The utility of plumage coloration for taxonomic and ecological studies. Open Ornithological Journal 2:17-23

Picardal JP, Afable FA, Lagman MCA, Campoto EA, Palada EP \& Valdez MB Jr. 2015. Phenotypic Characterization of Native Chickens (Gallus gallus domesticus) in Eastern Samar, Philippines. IAMURE International Journal of Ecology and Conservation 15(1):242

Saitou $\mathrm{N}$ and Nei M. 1987. The neighbor-joining method: A new method for reconstructing phylogenetic trees. Molecular Biology and Evolution 4(4):406425

Salces AJ, Yebron Jr MGN, Salces CB \& Dominguez JMD. 2015. Phenotypic and genetic characteristics of Boholano genetic group of Philippine native chicken (Gallus gallus domesticus, L.). Philippine Journal of Veterinary and Animal Sciences 41(1):1-11

Shand H. 1997. Human nature: agriculture biodiversity and farm-based food security. An independent study prepared by the Rural Advancement Foundation 


\section{Godinez, Nishibori \& Espina}

International for the Food and Agriculture Organization of the United State Nations. Ottawa, Canada

Smyth J. 1990. Genetics of plumage, skin, and eye pigmentation in chicken. In Crawford RD (ed) Poultry breeding and genetics. Amsterdam, Netherlands: Elsevier Science Publishers

Tamura K, Stecher G, Peterson D, Filipski A \& Kumar S. 2013. MEGA6: molecular evolutionary genetics analysis version 6.0. Molecular Biology and Evolution 30(12):2725-2729

Thompson JD, Higgins DG \& Gibson TJ. 1994. CLUSTAL W: improving the sensitivity of progressive multiple sequence alignment through sequence weighting, position-specific gap penalties and weight matrix choice. Nucleic Acids Research 22(22):4673-4680

Thomson VA, Lebrasseur O, Austin JJ, Hunt TL, Burney DA, Denham T, Rawlence NJ, Wood JR, Gongora J, Flink LG \& Linderholm A. 2014. Using ancient DNA to study the origins and dispersal of ancestral Polynesian chickens across the Pacific. Proceedings of the National Academy of Sciences 111(13):4826-4831

Yu M, Yue Z, Wu P, Wu DY, Mayer JA, Medina M, Widelitz RB, Jiang TX \& Chuong CM. 2004. The developmental biology of feather follicles. The International journal of developmental biology 48:181-191 
Qualitative traits and genetic characterization of native chicken

\section{SUPPLEMENTARY DATA}

List of sequences obtained from Genbank used in the phylogenetic analysis of native chickens in Samar Island, Philippines

\begin{tabular}{|c|c|c|c|c|}
\hline Source & Accession No. & $\begin{array}{l}\text { Haplo- } \\
\text { group }\end{array}$ & Origin & Reference \\
\hline Commercial layer & AM746033 & $\mathrm{A}$ & - & Muchadeyi et al 2008 \\
\hline Rhode Island red & AB268517 & A & - & Oka et al 2007 \\
\hline Commercial line & AM746035 & B & Japan & Muchadeyi et al 2008 \\
\hline Junglefowl & NC_007235 & B & Laos & Nishibori et al 2005 \\
\hline Junglefowl & NC_007236 & D1 & Philippine & Nishibori et al 2005 \\
\hline Junglefowl & NC_007237 & D1 & Indonesia & Nishibori et al 2005 \\
\hline White leghorn & AP003317 & E1 & - & Nishibori et al 2003 \\
\hline $\begin{array}{l}\text { White Plymouth } \\
\text { rock }\end{array}$ & AP003318 & E1 & - & Nishibori et al 2003 \\
\hline $\begin{array}{l}\text { New Hampshire } \\
\text { red }\end{array}$ & AY235571 & E1 & - & $\begin{array}{l}\text { Froman and Kirby } \\
2005\end{array}$ \\
\hline Coturnix japonica & AP003195.2 & outgroup & - & Nishibori et al 2001 \\
\hline
\end{tabular}

